\title{
Stage IV Hypopharyngeal Squamous Cell Carcinoma AJCC v7
}

National Cancer Institute

\section{Source}

National Cancer Institute. Stage IV Hypopharyngeal Squamous Cell Carcinoma A/CC v7. NCl Thesaurus. Code C8235.

Stage IV includes: IVA: (T4a, N0, M0); (T4a, N1, M0); (T1, N2, M0); (T2, N2, M0); (T3, N2, M0); (T4a, N2, M0); IVB: (T4b, Any N, M0); (Any T, N3, M0); IVC: (Any T, Any N, M1). T4a: Tumor with moderately advanced local disease. Tumor invades the thyroid/cricoid cartilage, hyoid bone, thyroid gland, or central compartment soft tissue. Central compartment soft tissue includes prelaryngeal strap muscles and subcutaneous fat. T1: Tumor limited to one subsite of hypopharynx and/or $2 \mathrm{~cm}$ or less in greatest dimension. T2: Tumor invades more than one subsite of the hypopharynx or an adjacent site, or measures more than $2 \mathrm{~cm}$ but not more than $4 \mathrm{~cm}$ in greatest diameter without fixation of hemilarynx. T3: Tumor measuring more than $4 \mathrm{~cm}$ in greatest dimension or tumor with fixation of hemilarynx or extension to esophagus. T4b: Tumor with very advanced local disease. Tumor invades prevertebral fascia, encases carotid artery, or involves mediastinal structures. N0: No regional lymph node metastasis. N1: Metastasis in a single ipsilateral lymph node, $3 \mathrm{~cm}$ or less in greatest dimension. N2: T umor with metastasis in a single ipsilateral lymph node, more than $3 \mathrm{~cm}$ but not more than $6 \mathrm{~cm}$ in greatest dimension, or in multiple ipsilateral lymph nodes, none more than $6 \mathrm{~cm}$ in greatest dimension, or in bilateral or contralateral lymph nodes, none more than $6 \mathrm{~cm}$ in greatest dimension. N3: Metastasis in a lymph node more than $6 \mathrm{~cm}$ in greatest dimension. M0: No distant metastasis. M1: Distant metastasis. (AJCC 7th ed.) 